University of Nebraska - Lincoln

DigitalCommons@University of Nebraska - Lincoln

The Nebraska Educator: A Student-Led Journal Department of Teaching, Learning and Teacher

Education

$10-2020$

\title{
Resources for Content-area Teachers Educating ELLs: A Literature Review
}

Heidi Jo Bartlett

University of Nebraska-Lincoln, hjbartlett@huskers.unl.edu

Follow this and additional works at: https://digitalcommons.unl.edu/nebeducator

Part of the Teacher Education and Professional Development Commons

Bartlett, Heidi Jo, "Resources for Content-area Teachers Educating ELLs: A Literature Review" (2020). The Nebraska Educator: A Student-Led Journal. 43.

https://digitalcommons.unl.edu/nebeducator/43

This Article is brought to you for free and open access by the Department of Teaching, Learning and Teacher Education at DigitalCommons@University of Nebraska - Lincoln. It has been accepted for inclusion in The Nebraska Educator: A Student-Led Journal by an authorized administrator of DigitalCommons@University of Nebraska - Lincoln. 


\title{
Resources for Content-area Teachers Educating ELLs: A Literature Review
}

\author{
Heidi Bartlett \\ Department of Teaching, Learning, and Teacher Education \\ University of Nebraska-Lincoln
}

\begin{abstract}
Educating English Language Learners (ELLs) is a rapidly growing need in K-12 schools. While often viewed as a homogeneous group, in reality this population is varied in terms of prior knowledge, access to formal education, age, and native language. Despite these differences, students must be taught first social, and then academic, English in order for them to be successful in their classes and graduate. While in previous decades, ELLs were isolated from the mainstream population, common education practices now integrate them into their grade-level classes. However, while working with this high-need population, mainstream content-area teachers often lack the time, professional knowledge, and/or resources to adequately help. This literature review, focusing primarily on resources for content-area teachers in grades 7-12 from a variety of settings, examines the challenges they face and how some of those challenges can be mitigated. Primarily, the problem must be acknowledged while support is given to teachers to plan and modify their lessons to help older learners who are at basic English proficiency levels. Additionally, students' prior knowledge and experiences must be incorporated into lessons, especially when making connections and in recognizing the funds of knowledge students have. An overreaching problem in the field, however, is that studying how to help older learner ELLs is an area that is drastically lacking, and there is definitely room for more focused research on this topic.
\end{abstract}

Keywords: secondary education, English Language Learners, ELLs, content-area teachers, resources

doi: 10.32873/unl.dc.ne011 


\section{Introduction}

Students in K-12 English as a Second Language (ESL) programs throughout the United States are a very diverse group. As of Fall 2016, approximately 4.6 million, or 9.6\%, of American students are classified as English Language Learners (ELLs) (National Center for Education Statistics, 2019), and they differ in age, native language, literacy skills, amount of formal education, time spent in English-speaking environments, motivation, and family support. Considering the wide range of students that must be educated to function in academic school settings, content-area teachers face an immense challenge in meeting students where they are in order to teach them for academic success. According to the Supreme Court decision Lau vs. Nichols in 1974, public schools are required to provide ELLs equal access to education and the accommodations necessary to learn both English and content subjects (Office for Civil Rights: US Department of Education, 2018).

Currently, most states utilize either the ACCESS test through WIDA or the ELPA 21 test through ELPA 21 to check English proficiency annually. Based on these assessments, English Learners (ELs) are either reclassified as English-proficient and exited out of ESL programs under monitoring status, or their scores indicate that they should remain with support for another year. Individual districts and schools are responsible for ensuring that students do not languish in the ESL program and for providing the needed support to exit. Although Annual Yearly Progress no longer needs to be shown to the same degree under the Every Student Succeeds Act (ESSA) as compared to the previous No Child Left Behind legislation, Nebraska has still set a goal that a student entering a school with no English proficiency should exit from the ESL 
program within five years. Indeed, Cummins (1981), a noted researcher in the field of second language acquisition, stated, "The finding that it takes at least five years, on the average, for immigrant children who arrive in the host country after the age of six to approach grade norms in L2 CALP [second language Cognitive Academic Language Proficiency] has important educational implications" (p. 148). This conclusion is in line with current Nebraska Department of Education guidelines for ELLs and ESL programs, which is outlined in the Nebraska ELL Program Guide (Nebraska English Learner Programs, 2017).

However, the greater academic load and variety in background knowledge of students entering the upper content courses means that content-area teachers frequently lack the resources to fully support the success of ELs in their courses. Harklau (1994) stated that “... the increased linguistic and academic demands made of older learners make integrated content-area programs, if anything, more crucial for them" (p. 269). Teaching at this upper level requires that students meet a higher standard for exiting ESL programs due to the higher academic and linguistic load. Aside from the use of scaffolding strategies that are generally effective in putting language in context for students, there seems to be little information available about specific curriculum or resources that are both effective for these grades AND that content-area teachers actually utilize. Acknowledging the lack of resources for content area teachers to better engage learning for ELL students is a necessary contribution to the field of education.

This literature review attempts to synthesize research in the field of secondary and postsecondary ESL, with an emphasis on resources available to 7-12 grade content-area teachers. Some studies are content-area specific, while others focus primarily on one of the language domains (such as writing) or culture. Often, researchers included strategies for the use of resources, and those have been included as appropriate. 


\section{Reframing Resources}

Frequently, when addressing the needs of resources in the classroom, there tends to be a focus on concrete materials such as books and supplemental worksheets. However, this framing of what resources entails neglects more intangible factors such as time and space (Wassell, Fernandez Hawrylak, \& LaVan, 2010). This narrative research study focused on recent high school graduates who were members of an ESL program at their school and who were enrolled in a bridge program. Researchers examined these intangible resources as provided by field observations and student interviews and concluded that while some of the roadblocks were due to larger educational structures, "teachers who empower ELL students to be productive learners encourage space and time to get to know their students better. This time and space grants students additional access to the curriculum and fosters opportunities for them to speak more English" (Wassell et al., 2010, p. 607). These findings imply that it may be necessary to train content-area teachers on attitudes and beliefs regarding ELLs and the resources that should be considered.

Another type of resource that is not always considered is human capital. To effectively teach English Language Learners, instructors must have not only knowledge of the content, but also understanding of how students acquire language, awareness of areas of potential difficulty, and strategies that can overcome the challenges. However, when trained ESL teachers are not available, the lack of experience and knowledge acts as a roadblock to learning. In one study, "Mainstream teachers were untrained in working with language learners, and ESL and mainstream curricula were not coordinated" (Harklau, 1994, p. 244). Therefore, when considering what type of resources a program has, we need to move beyond the idea of textbooks and technology to include intangible components as well. 


\section{Foundational Studies}

Many of the foundational studies in TESOL recognize the length of time needed to learn languages in immersion environments. Within the basic idea of a minimum of five years to learn well enough to be successful academically (Cummins, 1981; Hakuta, Butler, \& Witt, 2000), there is also an awareness of different types of instruction for older and younger learners.

In Short's (1994) work, she acknowledges the difficulties of older language learners. "Secondary students are at risk, not only because the time available in the K-12 structure runs out sooner for them but also because a large number of the new secondary student immigrating to the U.S. are underprepared for grade-level school work" (p. 582). She recommends that students receive both language and content-area instruction at levels that meet both levels of language and content knowledge (Short, 1994). This can be very difficult, as each secondary student in our schools will arrive with different levels of both, which can make developing standardized materials very time-consuming and challenging. Harklau (1994) supports these ideas, stating, "The content and course objectives of high school subject-area instruction presumed a relatively stable student population with a uniform knowledge base shaped by 8 or 9 years of previous instruction in U.S. elementary and middle schools" (p. 256). This assumption is what causes difficulties for learners in advanced grades as they enter the classroom without the needed knowledge base to be successful.

Indeed, Cummins (1981) relates that school districts may set an arbitrary limit to when services are provided to ELLs that are well below what data states is actually needed. However, since this research about student needs was from 1981, one can hope that more school districts have recognized the importance of providing scaffolded support until students have been deemed proficient enough to succeed academically without support. 
In another analysis of different studies (Hakuta et al., 2000), experienced researchers, including Hakuta - a foundational researcher in the field of second language acquisition investigated previous claims regarding the length of time needed to obtain proficiency. Reviewing the length of time the ESL students attended school in either the US or Canada, the researchers concluded that students needed a minimum of five years to be on par with native speaking students in an academic setting, a conclusion that echoed Cummins' earlier research.

In many states, students have a limited amount of time to be exited from the ESL programs. This study and previous studies from the 1970s to the early 2000s repeatedly show that a minimum of five years is necessary for academic success and fluency. In Nebraska, the current goal is five years to exit an emergent bilingual from an ESL program. However, terms such as success and fluency need to be operationalized and defined in order to ensure that research is consistent. Additionally, the researchers stated that five years was the minimum length of time necessary and that more time may be needed for some students to obtain fluency. The research also showed that socioeconomic status was a factor in the length of time needed to obtain fluency (Hakuta et al., 2000) which is a factor not always accounted for in research centered on language acquisition.

\section{Content-area Instruction: Social Studies}

One direction that studies take is the focus on content-area instruction for language learners. Students frequently face challenges as they are integrated into mainstream classrooms, especially when teachers are unaware of resources and strategies to best assist language learners in acquiring both content and language. However, since ELLs are in mainstream classrooms more frequently than ELL-specific classrooms once they are able to communicate socially, content- 
area instruction is a high-need area where teachers need to be aware of the complications when teaching this population.

The content area of social studies seems to be a popular area for research. In one study, Duff (2001) wanted to examine challenges of ESL students in mainstream classrooms and how those challenges were met and focused on the intersection of language, literacy, and culture. In one of two mainstream $10^{\text {th }}$ grade social studies teachers' classes, both native-speaker and nonnative-speakers were observed and interviewed for their perspectives about the challenges, and their responses were transcribed and analyzed for themes (Duff, 2001).

One theme that arose when discussing difficulties was regarding resources. In this study, the textbook used in the classes was outdated and written from a white male perspective. Therefore, the teachers supplemented or supplanted the textbook with other readings. Unfortunately, since these readings were collected at the end of class, the students could not refer back to them later or take them home for further study. As the teachers included multiple historical perspectives by inviting guest speakers, classes focused more on oral skills and listening, with few resources such as pictures or diagrams for the ESL students to reference (Duff, 2001). Therefore, even when the social studies teachers strived to make the classes relevant and engaging, many of the students reported that they felt lost during the presentations because of the lack of scaffolding. Although teachers may think they are providing sufficient scaffolding to allow for student comprehension of the topic, students frequently need more than what is provided. Teachers need to think about their course curriculum, resources, and necessary background knowledge in order to help ESL students succeed in their classes.

The resources available to secondary content-area teachers are going to vary by grade and subject. However, among these differences, social studies is a subject area which many ELLs 
find interesting due to their life experiences (Short, 1994). In a study that examined the effectiveness of a social studies unit developed for middle school students, Short (1994) enumerated several challenges. One of the primary difficulties was the level of literacy needed to read authentic texts; however, demanding writing requirements, the integrative model of content across grade levels, and the expository textbooks also posed significant challenges to learners (Short, 1994). In her study, these obstacles were addressed through the use of graphic organizers to understand writing and reading organization, the use of supplemental texts to bring the information to a level accessible to students, and cooperative learning tasks to increase communication skills. One advantage that Short (1994) found in her study was that the academic language used in middle school classrooms was frequently on par with other types of academic discourse, with less jargon than might be expected in a subject such as science. From this study, a key conclusion was that language objectives are a requirement when developing lesson plans, and that time, effort, and collaboration are necessary when developing units (Short, 1994). Therefore, when content-area teachers' time or knowledge to develop such effective units and lessons are lacking, our ELL students are often relegated to having to read out of textbooks that are beyond their level and gaining little from the class.

In another study focusing on high school social studies, researchers focused on creating a supportive classroom while reducing cognitive load and explicitly teaching academic skills (Szpara \& Ahmad, 2007). This study echoed many of the same difficulties identified by other researchers (Duff, 2001; Short, 1994), but were aided by working with five experienced social studies teachers who were interested in participating in the project. One of the strategies that they focused on was teaching the use of academic resources such as dictionaries (English only) and first language knowledge to rephrase or understand the authentic texts. As translated social 
studies textbooks are rare, teachers had to utilize other strategies to reduce the cognitive load of the materials (Szpara \& Ahmad, 2007) such as incorporating textbooks from younger grades or guided notetaking. The researchers noted a key difference between ELLs and native-speakers: "Students who speak English as a native language can find and sort key information on their own from either verbal or written sources. In contrast, ELLs' primary responsibility is to understand new information rather than spend time finding it" (Szpara \& Ahmad, 2007, p. 193). This shift in a lesson's focus requires a change in thinking about the class aims on the part of the contentarea teacher, and it must be acknowledged that the ELLs' primary goal in the classroom is going to be different from a native-speakers'. Both linguistic and content-specific objectives must be developed, addressed, and supported during classes. Again, this requires more professional development for mainstream teachers or collaboration between ESL and content-area teachers.

In another study, Cho and Reich (2008) focused on 33 social studies teachers in six high schools in Virginia, which were target schools for ESL learners. Although ELLs come from a variety of diverse backgrounds and educational histories, many schools use the ELL label as if students were a homogeneous group, which can be problematic. Despite these varied backgrounds, previous research has supported the conclusion that it is beneficial for students to learn both content knowledge and language at the same time. However, some content-area teachers do not agree with this conclusion, as they believe that students would be better placed in isolated language-specific settings where they can receive alternate instruction until they are ready to participate in mainstream classes (Cho \& Reich, 2008).

To obtain data from the social studies teachers, Cho and Reich distributed surveys at professional development meetings at the schools and collected them the next day. From the results of the survey, one of the biggest challenges for the social studies teachers was the ELL 
students' lack of background knowledge of their area, with $70.6 \%$ responding that this one of their top three challenges. In asking about types of classroom supports, many teachers responded that they provided extra time to complete work (Cho \& Reich, 2008). However, according to the survey, teachers rarely or never provided alternative assessments or instructional materials to students. Later in the survey, over $75 \%$ of the respondents indicated that professional development about ESL instructional strategies would be very important or important to them. When we look at the results from the non-traditional view of resources (Wassell et al., 2010), we see that the teachers provide some assistance, while lacking in the resources that cost more in time, knowledge, or money (Cho \& Reich, 2008).

Regardless, more collaboration with the ESL instructors at the schools, as well as greater communication within departments and between schools, may provide additional support and resources that content-area teachers could develop and provide to students. From a survey like this one, it appears that many teachers claim to be open to receiving more information about how to serve this population better, but may not know where to start in their own classrooms.

\section{Language Domain: Reading}

Among all of the different content areas, having literacy skills is a key component that leads to success in secondary grades. When students are not successful in reading, it is less likely that they will find success in content-area classes. In a study concerning the efficacy of reading interventions, Callahan (2010) compared English language development (ELD) curriculum at a high school in California where approximately $37 \%$ of the 2000 students at the high school spoke a language other than English at home. With the treatment of the reading intervention program that focused on students in the lowest quartile of reading proficiency, Callahan investigated if the program was effective and if ELLs were being appropriately served 
by the new program. As part of the data collection and analysis, long-term ELLs (defined in the study as attending a US school for more than seven years) were also compared to recent immigrants (attending a US school for less than five years) to examine if there were a difference between these two populations and reading program efficacy (Callahan, 2010). Callahan's results showed that long-term ELLs scored worse than recent immigrants in the reading intervention program. More problematically, many of the students who had previously participated in an ELD course were no longer eligible for the reading interventions as they scored too high on the reading proficiency tests, which led to those students not receiving any English support. The differences in test scores, although small, were statistically significant and had the potential to lead to differences in decisions about students (not) being reclassified as ELLs (Callahan, 2010). Therefore, when districts make decisions about academic interventions, they must ensure that the resources being provided are not only useful to teachers, but do not harm the students in their application.

In Callahan's (2010) research, he states the important point, "Learning English does not occur in isolation, rather it is highly context dependent" (p. 3). The idea that English academic instruction is tied to the course content along with instruction about the English language is key to increasing language proficiency. The most effective strategies and resources are going to include both aspect of language learning. Along with considering both aspects, it is vital that the resources available to schools and students be level appropriate and neither too high nor too low.

When focusing on the intersection of reading and ELLs, according to Brown (2007), reading social studies texts specifically places a large burden on students. Social studies texts present a unique challenge in the content area because of its advanced vocabulary, complex syntax, decontextualized information, and assumption of background knowledge. These are 
hurdles to overcome for any student not reading at grade level, but challenges are multiplied for ELLs. To combat these, Brown (2007) suggests lexiling texts to make the vocabulary and grammar easier, using guided questions and outlines to keep students on track while reading, and utilizing concept maps to address gaps in knowledge. While not new strategies, these techniques do not address is the fact that these scaffolded resources are not immediately available to content-area teachers, and their use is dependent on the teachers' ability to scaffold the written material and time to develop such modifications. Therefore, to be successful, these strategies encompass both the material resources available to teachers as well as the availability of intangible resources.

\section{Language Domain: Culture}

Learning about culture is an integral part of learning about language. Without the cultural knowledge of how to use language appropriately in different settings, learning vocabulary and grammar is of limited use. Throughout the world, however, information about the cultural aspect

of languages is frequently placed in secondary importance compared to grammar. Specifically, it asked how international teachers in countries with a national curriculum are implementing cultural knowledge and the degree to which intercultural competence is addressed in the classroom (Lavrenteva \& Orland-Barak, 2015).

This study took data from 14 countries with nationalized English curriculums that had information available online for their secondary curricula. The areas that these countries drew from included Asia (2), South America (3), Northern Africa (2), Eastern Europe (4), and Northern Europe (3). The curricula were examined in four dimensions: subject matter, learner, teacher, and milieu. Analysis of the curricula revealed that many countries had similar foci and encouraged that students learn about the attitudes and viewpoints of other cultures while 
comparing them to their native cultures (Lavrenteva \& Orland-Barak, 2015). Teachers were generally given a lot of leeway in deciding how to implement the curricula and learning objectives.

Unfortunately, this was another empirical study that was not focused on content-area secondary schools and classrooms. However, from this study, we can draw applicable conclusions, most noteworthy that culture is integral to learning a language. The researchers noted that this study lacked information about how the curricular resources and materials addressed culture, so this could be an area of future research. Our content-area teachers will need to consider the cultural aspect to the information they are providing students. Even areas that teachers might view as free from culture, such as math, has cultural components integrated with linguistic components, which need to be addressed and taught to our emergent bilingual students.

Examining culture from another angle, other researchers have examined the relationship between culture and content areas. Lee and Buxton stated, "Because science has traditionally been regarded as culture-free, incorporation of home culture into science instruction has not been adequately conceptualized" (2013, p. 40). This means that science teachers are often unprepared to consider students' home cultures and what that means for language instruction and the background knowledge that students bring. To improve students' understanding of science, teachers need to realize that content instruction is not "culture-free", as everything in education must be situated in context.

\section{Language Domain: Writing}

English learners as a population often lag behind in academic writing skills as compared to their oracy skills. In this study, Ramos (2014) worked with a class of 20 public high school 
ELLs over a period of eight weeks to improve their writing skills with the Reading to Learn curriculum in the northeastern United States. Reading to Learn deconstructs texts with teacher assistance and scaffolding to allow students to better manipulate written language. Academic English has very specific writing conventions that are expected in order to be successful; therefore, a persuasive essay was the goal of this unit and this study. The students in this study had scored less in in written language skills than in oral language skills, so the goal was to teach specific writing and reading skills have more success later in their high school careers and in postsecondary education (Ramos, 2014).

In the study, pre- and posttests were scored using Functional Language analysis as well as with a more student-friendly tool designed by Ramos titled the Performance Criteria and Assessment Tool (Ramos, 2014). The curriculum was separated into five different stages: Building Field Stage (scaffolding and providing background context), Preparing to Read Stage (providing purpose for a persuasive essay), Detailed Reading Stage (informing about academic writing conventions), Joint Construction Stage (writing a persuasive essay as a class with teacher support), and Individual Construction Stage (student independently writing a persuasive essay). These stages were scaffolded to allow for students to gradually increase their skills and responsibility for their own learning, and posttest results showed that student writing became more complex and organized when compared to their pretest scores (Ramos, 2014).

While this study focused on an ESL classroom without a content-area course as a counterpart, it did provide conclusions about how certain curricula and teaching techniques could be helpful in encouraging academic skills with students. The scaffolded strategies and systematic instruction could provide relevant starting points for addressing learners' needs. However, if content-area teachers do not recognize writing as a set of processes, then they may 
not know how to divide the task into its requisite components to encourage student success. Like other areas of language instruction, teaching academic writing requires pedagogical, content, and linguistic skills.

Changing educational standards now focus on ensuring that all students are career and college ready, and this includes students in adult education programs. As our emergent bilinguals are not always able to graduate high school before they are 21 years old, or often drop out before graduating, I expanded the scope of my literature review slightly to examine if post-secondary resources were either more available or more effective in teaching learners. In the U.S. as a whole, the on-time graduation rate in 2016 for ELs was $67 \%$ compared to $85 \%$ for non-ELs. In Nebraska, the difference in graduation rate was even more drastic, with a rate of $54.5 \%$ for ELs and $90.3 \%$ for non-ELs - a discrepancy of 35.8\% (Department of Education, 2018). These low rates of on-time graduation for language learners clearly indicate that there are deficiencies that are not being addressed in secondary schools.

Writing skills are essential to the education process and life outside of school. This study acknowledged that many adults in community colleges and other post-secondary settings do not finish their degree or program within six years, and this could be partially due to the need for remedial courses at post-secondary levels (Fernandez, Peyton, \& Schaetzel, 2017). Adults in such settings come from a wide variety of backgrounds and can include students both with and without a diploma from an American high school. Knowing more about how their high school students will use their knowledge of writing in post-secondary life may help content-area teachers to develop relevant resources and exercises which students will find practical applications for. 
Due to these differing needs, Fernandez, Peyton, and Schaetzel (2017) surveyed instructors who taught adult ESL courses and asked them a variety of questions focused on their views of writing importance, types of writing practices, support for writing, and ways to encourage student success. The 43-question survey had 471 participants who completed at least part of the survey. Examination of the results indicated that most students wrote less than one page per week, with lower-proficiency students writing even less. However, respondents indicated that writing was not often tested in determining class placement, and that reading was a larger focus than writing in their programs. Positives to the responses showed that teachers were together with their students regularly, and class sizes were small - both attributes which would be expected to benefit students in a writing class (Fernandez et al., 2017). This is definitely a situation where the instructors may have had the material resources to teach and test writing, but the time and support for this language domain was lacking.

With these results at the postsecondary level, we could expand these conclusions to the contemplation that many ESL students in K-12 settings are not receiving enough writing practice, or concentrated lessons about writing, in their classes due to emphasis on other linguistic skills or content knowledge. Therefore, when students move to content-area classes which require different types of in-depth writing, they may not be sufficiently prepared. ESL teachers and content-area teachers need to examine their curriculum, goals, and expectations to ensure that support is being provided throughout the writing process with appropriate feedback for improvement.

In another study that examined higher-order language use in writing, Mueller and Jacobsen (2015) examined the resources of online dictionaries and corpora to provide students with strategies when they do not know the correct vocabulary to use. Online corpus use has been 
a recent area of research in language education as teachers have examined ways to utilize them in classrooms to increase student learning of either vocabulary or correct grammar. These would be especially helpful in the areas of feedback and error correction with written language. This study had two experiments - one examining student perspectives about using an online corpus $(n=78)$ and one investigating if online dictionaries or corpora were more beneficial for collocation and register difficulties $(\mathrm{n}=39)$ (Mueller \& Jacobsen, 2015).

While the participants in this study were undergraduate females attending a university in Japan taking EFL courses, the ideas concerning the utilization of resources are still applicable to secondary education in the United States. From the first experiment, it was concluded that lower-proficiency learners have difficulty using corpora in an effective manner. From the second experiment, it was determined that students needed more time to learn how to use corpora but were ultimately more successful in gap-fill tests using corpora compared to using an online dictionary (Mueller \& Jacobsen, 2015).

A key idea from the results of this study is that instructors need to ensure that appropriate support is provided to ESL students so that they understand how to use the resources and their circumstances for use. Generally, lower-proficiency students have a more difficult time compared to higher-proficiency students when it comes to learning how to utilize language resources. Educators cannot assume that emergent bilinguals are able to use resources effectively. Because of varying skills on the part of students, different types of resources intended to be helpful may actually require more support from the content-area teachers as well as the language-specific teachers in assisting students to learn how to use the resources independently, especially when new. 


\section{Conclusion}

From the different studies and considerations of the results as it relates to classroom resources, there seems to be a few common themes that would benefit the field of secondary emergent bilinguals. First, content-area teachers frequently lack either the knowledge or the time (or both) to modify existing resources such as textbooks to better suit the needs of our language learners. Second, secondary students (grades 7-12) who enter as newcomers are at a disadvantage not only due to language constraints, but also due to assumptions about common life experiences and the pressure of earning credits toward graduation quickly. When contentarea teachers do not think about or plan for the assumed cultural knowledge needed to be successful in a task, it increases the already heavy linguistic burden that students carry.

Third, systematic support is needed both for emergent bilinguals AND content-area teachers. For students, support could mean pre-teaching vocabulary, learning how to write extended discourse in English, or safe spaces to practice classroom speaking. For mainstream teachers, support could be modeling effective teaching with strategies such as utilizing graphic organizers, conversations with the ELL team to discuss specific student needs and experiences, or learning how to rewrite texts to be level-appropriate. Regardless of what the support looks like in schools, support is both federally mandated for students AND leads to better learning outcomes when people are able to access the help they need.

However, in analyzing the research concerning where 7-12 grade ELLs need the most resources and support, it has become obvious that this entire field is lacking in empirical research. From what studies we do have, it is clear that support and resources are underprovided when teaching our older language learners. This could be due to several reasons. For one, students who are classified as ELL in kindergarten are often exited out of an ELL program by the 
time they reach high school. As students enter ELL programs at an older age, the gap between their language skills and what their grade-level peers are learning in their content areas is wide. Failing adequate resources and education on the topic, content-area teachers may neglect to support these students in ways that are beneficial for decreasing that gap and for future learning.

Another point is that not only does there need to be more research in general, there also needs to be more research in content areas other than social studies. I'm not sure why this content area seems to be more prevalent than science or English Language Arts, for example. However, it could be due to multiple factors, not least of which that many people consider social studies to be less important than math or reading (as an "untested" subject), and could therefore be easier to receive permission from school districts for research in this content area.

Finally, where there is research, it tends to focus on specific content areas such as social studies, with others, such as math, lacking in research. Due to the paucity of research, any type of empirical study that concentrates on secondary ELLs would benefit the field of teaching English to speakers of other languages. Areas for further research could take a variety of directions: successful strategies utilized in classes with ELLs by content-area teachers and by ELL teachers, longitudinal studies which follow the success (or not) of ELLs in order to find factors which lead to timely high school graduation, textbooks or supplemental resources that are scaffolded and lexiled for learning, or development of resources that are useful to an emergent bilingual population that has rich life experiences which don't match their English language ability. Any study of this type could help provide starting points in expanding this field to encompass the great variety of students and situations that we serve. Additionally, Wassell et al. noted that much of the current research is focused on deficit views of teaching language learners; 
teachers need to be aware of this approach towards research in order to acknowledge a needed shift in research (2010).

In K-12 education, we want our students to be prepared for their later life goals.

Language skills are an important component of this goal. As teachers, we need to recognize the challenges and strengths that language learners bring to our classrooms while working with students to overcome weaknesses. While working with emergent bilinguals may be unfamiliar to some content-area teachers, it is important that teachers educate themselves about their needs and work to integrate teaching strategies that can compensate for developing English skills. As educators, we must ensure that student life goals are met and that our students are supported along the way to success. 


\section{References}

Brown, C. L. (2007). Strategies for making social studies texts more comprehensible for Englishlanguage learners. The Social Studies, (October), 185-188.

Callahan, R. M. (2010). The intersection of accountability and language: Can reading intervention replace English language development? Bilingual Research Journal, 30(1), 121. https://doi.org/10.1080/15235882.2006.10162863

Cho, S., \& Reich, G. A. (2008). New immigrants, new challenges: High school social studies teachers and English language learner instruction. The Social Studies, (November/ December), 235-242.

Cummins, J. (1981). Age on arrival and immigrant second language learning in Canada: A reassessment. Applied Linguistics, 11(2), 132-149. https://doi.org/10.1093/applin/2.2.132

Department of Education. (February 2018). Academic performance and outcomes for English learners. Retrieved from https://www2.ed.gov/datastory/el-outcomes/index.html\#two

Duff, P. A. (2001). Language, literacy, content, and (pop) culture: Challenges for ESL students in mainstream courses. The Canadian Modern Languages Review/La Revue Canadienne Des Langues Vivantes, 58(1), 103-132.

Fernandez, R., Peyton, J. K., \& Schaetzel, K. (2017). A survey of writing instruction in adult ESL programs: Are teaching practices meeting adult learner needs? Journal of Research and Practice for Adult Literacy, Secondary, and Basic Education, 6(2), 5-20.

Hakuta, K., Butler, Y. G., \& Witt, D. (2000). How long does it take English learners to attain proficiency?

Harklau, L. (1994). ESL versus mainstream classes: Contrasting L2 learning environments. TESOL Quarterly, 28(2), 241-272.

Lavrenteva, E., \& Orland-Barak, L. (2015). The treatment of culture in the foreign language curriculum: An analysis of national curriculum documents. Journal of Curriculum Studies, 47(5), 653-684. https://doi.org/http://dx.doi.org/10.1080/00220272.2015.1056233

Lee, O., \& Buxton, C. A. (2013). Integrating science And English proficiency for English language learners. Theory Into Practice, 52, 36-42. 
https://doi.org/10.1080/07351690.2013.743772

Mueller, C. M., \& Jacobsen, N. D. (2015). A comparison of the effectiveness of EFL students' use of dictionaries and an online corpus for the enhancement of revision skills. ReCALL, 28(1), 3-21. https://doi.org/10.1017/S0958344015000142

National Center for Education Statistics. (May 2019). English language learners in public schools. Retrieved from https://nces.ed.gov/programs/coe/indicator_cgf.asp\#info

Nebraska English Learner Programs. (2017). Nebraska ELL program guide: Guide for teachers. Nebraska Department of Education. https://cdn.education.ne.gov/wpcontent/uploads/2017/10/NDE-Teacher-Program-Guide-2017-updates.pdf

Office for Civil Rights: US Department of Education. (25 September 2018). Developing programs for English language learners: Lau v. Nichols. Retrieved from https://www2.ed.gov/about/offices/list/ocr/ell/lau.html

Ramos, K. (2014). Teaching adolescent ELs to write academic-style persuasive essays. Journal of Adolescent \& Adult Literacy, 57(8), 655-665. https://doi.org/10.1002/jaal.303

Short, D. J. (1994). Expanding middle school horizons: Integrating language, culture, and social studies. TESOL Quarterly, 28(3), 581-608.

Szpara, M. Y., \& Ahmad, I. (2007). Supporting English-language learners in social studies class: Results from a study of high school teachers. The Social Studies, (October), 187-195.

Wassell, B. A., Fernandez Hawrylak, M., \& LaVan, S.-K. (2010). Examining the structures that impact English language learners ' agency in urban high schools: Resources and roadblocks in the classroom. Education and Urban Society, 42(5), 599-619. https://doi.org/10.1177/0013124510375598 